To the Editors:

\title{
Age of onset of menarche and secondary sexual characters in Sri Lankan girls of two different regions
}

Improvement in nutritional status has advanced the ages of onset of pubertal changes and menarche. Although there have been studies done in Sri Lanka from time to time, comparison has been difficult due to differences in methodology. A longitudinal study in 1984 showed the mean age of menarche (MAM) to be 13.7 years (SD 1.3) $[1,2]$. Another study in 1988 based on probit analysis showed the MAM to be 11.8 years [3]. This study aimed to identify the patterns of onset of secondary sexual characteristics in girls at different ages and the MAM in a group of Sri Lankan children.

A cross-sectional descriptive study was carried out among school girls of two different administrative districts, Colombo and Kalutara, in the western province of Sri Lanka. 
Seven to 16-year old girls who did not suffer from any significant ill health were randomly recruited from schools. A minimum of 50 subjects in each age group were recruited from each district. Breast and pubic hair development was staged according to the 5-stages described by Tanner [4]. Axillary hair was classified using a 3 stage scale [5]. The scale is; $1=$ no axillary hair; $2=$ slight growth of axillary hair and $3=$ adult distribution. MAM was calculated using the status-quo method [6]. Assessments were done by four authors (VPW, TUN de S, HHP and ANK de S). Girls without pubic hair (stage P1) and breast development (stage B1) were denoted as "prepubertal". Girls with pubic hair (stages P2-P4) and/or axillary hair (stage 2) alone were denoted as "adrenarche". Signs of breast development alone (stages B2 - B4) was denoted as "thelarche". Those who were having both thelarche and adrenarche were identified as "pubertal", and those with adult stages of breast development (stage B5) and pubic hair (stage P5) and/or axillary hair (stage 3) together were considered as "adult".

Estimation for the mean ages of entry into each pubertal stage (stage 2 and above) was calculated using probit analysis [7]. Data were analysed using the NCSS 2000 (Hintze JL, Kayswille, Utah, USA) statistical computer package. The Ethical Review Committee of the Faculty of Medicine, University of Colombo approved this study.

One thousand eight hundred and fifty girls were studied. All were of Sinhalese ethnicity. Table 1 shows the proportion of girls with different pubertal stages according to each age category for the entire study population. Table 2 shows the mean ages of attaining menarche and stage 2 or above for each secondary sexual characteristic for each district as well as for the whole population.
Breast development was the first secondary sexual character to appear. Of the 7-year old girls, $2.2 \%$ and $6.6 \%$ had B2 breast development in the Colombo and Kalutara groups respectively. In both districts pubic hair development was seen one year later. The distribution of girls attaining each secondary sexual characteristics and onset of menarche for each age category was similar in both districts. In both districts onset of menarche was seen at 8 years, and by 15 years all girls had attained menarche. The median age of menarche was 11.2 years (SE 0.057) (table 2). The median age of attaining "adult" state was 15.5 years (SE 0.15 years).

Previous studies on Sri Lankan girls have shown differences in mean age of onset of puberty [1-3]. In addition to the secular trend, differences in methodology would have contributed to the changes in estimates, thus making them difficult to compare. In a study done among Sinhalese girls in 1976 MAM assessed by recall was 13.5 years, but when calculated using probit analysis was 13.8 years [8]. A study carried out in 1984 using the same methodology showed MAM to be $13.06 \pm 0.18$ years [9], while another published in 1988 showed MAM to be 13.01 years among children in state schools in a suburb of Colombo and 11.78 years in children from affluent private schools in Colombo [3]. MAM in our study was 11.2 years.

The apparent reduction in the median age of onset of pubertal staging over the years may be due to improvement in nutritional status, reduction of infections and overall improvement in socio-economic status. Larger, nationally representative studies that include all ethnic groups and social classes are required to investigate these aspects.

Table 1. Proportion of girls with different pubertal status according to age

\begin{tabular}{lccccc}
\hline Age group & Prepubertal \% & Thelarche \% & Adrenarche $\%$ & Pubertal \% & Adult \% \\
\hline 7-7.9 years & 97.8 & 2.2 & 0 & 0 & 0 \\
8-8.9 years & 82.9 & 5.5 & 7.5 & 4.1 & 0 \\
9-9.9 years & 48.8 & 26.5 & 5.7 & 19.0 & 0 \\
$10-10.9$ years & 8.5 & 12.6 & 4.1 & 74.5 & 0 \\
$11-11.9$ years & 1.0 & 5.1 & 2.5 & 91.4 & 0 \\
$12-12.9$ years & 0.9 & 0 & 1.3 & 91.4 & 0 \\
$13-13.9$ years & 0 & 0 & 0 & 89.0 & 11.0 \\
$14-14.9$ years & 0 & 0 & 0 & 60.4 & 39.6 \\
$15-15.9$ years & 0 & 0 & 0 & 36.0 & 64.0 \\
$16-16.9$ years & 0 & 0 & 0 & 43.0 & 57.0 \\
\hline
\end{tabular}


Table 2. Median age and standard error of attaining menarche and stage 2 or above of each secondary sexual characteristic in the study group assessed by probit analysis

\begin{tabular}{lcccccc}
\hline & \multicolumn{2}{c}{ Kalutara } & \multicolumn{2}{c}{ Colombo } & \multicolumn{2}{c}{ Combined } \\
\cline { 2 - 6 } & $\begin{array}{c}\text { Median } \\
(y r s)\end{array}$ & $\begin{array}{c}S E \\
(y r s)\end{array}$ & $\begin{array}{c}\text { Median } \\
\text { Age (yrs) })\end{array}$ & $\begin{array}{c}\text { SE } \\
(y r s)\end{array}$ & $\begin{array}{c}\text { Median } \\
\text { Age (yrs) }\end{array}$ & $\begin{array}{c}\text { SE } \\
(y r s)\end{array}$ \\
\hline Breast $\geq 2$ & 9.1 & 0.081 & 9.1 & 0.096 & 9.1 & 0.053 \\
Pubic hair $\geq 2$ & 10.0 & 0.083 & 9.6 & 0.079 & 9.8 & 0.057 \\
Axillary hair $\geq 2$ & 10.1 & 0.088 & 10.0 & 0.080 & 10.1 & 0.057 \\
Menarche & 11.2 & 0.085 & 11.2 & 0.083 & 11.2 & 0.057 \\
\hline
\end{tabular}

\section{References}

1. Rajapakse L, Kodagoda N. Some development characteristics of Sri Lankan adolescent females - 1.97th Anniversary Academic Sessions, Sri Lanka Medical Association 1984; Abstract No 35:17-8.

2 Rajapakse L, Kodagoda N. Some development characteristics of Sri Lankan adolescent females - 2. 97th Anniversary Academic Sessions, Sri Lanka Medical Association 1984; Abstract No 36:18-9.

3 Godawatta R, Wikramanayake TW. Some factors influencing the age at menarche of Sri Lankans. Ceylon Journal of Medical Sciences 1988; 31: 53-69.

4 Tanner JM. Growth at Adolescence. Oxford: Blackwell Scientific, 1962.
5 Malina RM, Bouchard C. Growth maturation and physical activity. Human kinetics, Champaig, IL, 1991.

6. Herman-Giddens ME, Slora EJ, Wasserman RC, Bourdony CJ, Bhapkar MV, Koch GG, Hasemeier CM. Secondary sexual characteristics and menses in young girls seen in office practice: a study from the Paediatric Research in Office Setting Network. Paediatrics 1997; 99: 505-12.

7 Finney DJ. Probit Analysis. Cambridge: Cambridge University Press, 1971

8 Balasuriya S, Fernando MA. Age at menarche in three districts in Sri Lanka. Ceylon Medical Journal 1983; 28: 227-31.

9 Jayasekara R, Goonewardene S. The influence of socioeconomic factors on mean age of menarche in Sri Lanka. Ceylon Medical Journal 1987; 32: 89-94.

V P Wickramasinghe ${ }^{1}$, T U N De Silva ${ }^{2}$, H H Patabenda ${ }^{3}$, A N K De Silva $^{2}$, L Rajapakse ${ }^{4}$ and Sanath P Lamabadusuriya ${ }^{1}$ ${ }^{1}$ Department of Paediatrics, and Department of Community Medicine, Faculty of Medicine, University of Colombo, ${ }^{2}$ Lady Ridgeway Hospital, Colombo and ${ }^{3}$ District Hospital, Matugama, Sri Lanka.

Correspondence: VPW, e-mail: <pujithaw@yahoo.com>. Received 14 May 2008 and revised version accepted 9 October 2008. Competing interests: none declared. 